\title{
Prolonged Inhaled Allergen Exposure Can Induce Persistent Tolerance
}

\author{
Chris L. Van Hove, Tania Maes, Guy F. Joos, and Kurt G. Tournoy \\ Ghent University, Faculty of Medicine and Ghent University Hospital, Department of Respiratory Diseases, Ghent, Belgium
}

\begin{abstract}
Murine asthma models suggest that failure of immune tolerance rather than a defective Thelper cell type 1 (Th1) immunity underlies the immune biology of Th2-driven allergen-induced airway disease. Intriguingly, prolonged exposures can result in a full waning of inflammation. The mechanisms underlying this observation are not understood. We hypothesized that the fading of inflammation is the result of regulatory processes, characterized by altered dendritic cell (DC)-T cell interactions. First, we implemented a model in which mice developed Th2-driven airway disease. When we subjected these mice to prolonged antigen ovalbumin (OVA) exposures (8 wk), all inflammation disappeared. Re-immunization and re-challenge showed an inability to mount Th2-skewed immune responses, with absence of airway eosinophils, IgE, and Th2 cytokines. Besides specific immune tolerance, bystander protection was observed. A decrease in $\mathrm{CD}^{+} \mathrm{CD}^{+} 5^{+} \mathrm{Foxp}^{+}{ }^{+}$-regulatory cells, PD-1, and IL-10 expression was discerned as compared with acute inflammation. In addition, suppression of ICOS and CD28 was found, along with inhibited DC maturation. This process of disease inhibition surprisingly had a long-lasting memory and was not caused by endotoxin signaling through TLR-4. In summary, our results indicate that the disappearance of Th2-driven airway disease upon persistent antigen exposure is associated with the induction of immune tolerance. The tolerant state is antigen-dependent, and extends to bystander antigens. Moreover, this tolerance is characterized by an altered DC-T cell communication and is long-lasting. Our data further suggest that the mechanism of the disease inhibition after allergic airway inflammation differs from the anti-inflammatory mechanisms observed during acute eosinophilic airway inflammation.
\end{abstract}

Keywords: asthma; airway inflammation; co-stimulation; mouse models; tolerance

Both experimental and clinical data provide abundant evidence for the central role of activated T helper type 2 (Th2) cells in the allergen-induced airway inflammation observed in asthma (1). A number of murine asthma models mimic the features of this disease and allow the study of underlying cellular and molecular mechanisms (2). The Th2-driven airway changes in these models are mainly evoked by exposure of the airways to the archetypic antigen ovalbumin (OVA) for 2-7 d after systemic sensitization.

Based on these animal models but also on growing clinical data, a change in paradigm has recently been proposed in which, instead of a Th1/Th-2 imbalance, failing tolerance mechanisms are thought to be decisive in the pathogenesis of Th2-driven allergic airway disease (3). This view is plausible because toler-

\footnotetext{
(Received in original form October 13, 2006 and in final form December 29, 2006) This project is supported by the Fund for Scientific Research - Flanders (FWOVlaanderen); Project G.0052.06. K.G.T. is a senior clinical investigator with grants from the Fund for Scientific Research Flanders (FWO-Vlaanderen).

Correspondence and requests for reprints should be addressed to K. G. Tournoy, M.D., Ph.D., Department of Respiratory Diseases, Ghent University Hospital 7K12 I.E., De Pintelaan 185, 9000 Ghent, Belgium. E-mail: kurt.tournoy@UGent.be

Am J Respir Cell Mol Biol Vol 36. pp 573-584, 2007

Originally Published in Press as DOI: 10.1165/rcmb.2006-03850C on January 11, 2007

Internet address: www.atsjournals.org
}

\section{CLINICAL RELEVANCE}

It becomes clear now that a failure of immune tolerance explains allergic airway inflammation. Our data demonstrate that despite allergen exposure, immune tolerance can be restored. In addition, our research characterizes the immune mechanisms involved.

ance is the normal functional outcome after allergen exposure in healthy nonatopic individuals or nonsensitized naïve animals. In addition, it has been shown that mice, made tolerant by means of inhalation or feeding of OVA, are protected against subsequent allergen-induced airway disease, mainly due to the effects of $\mathrm{CD}^{+} \mathrm{CD}^{2} 5^{+} \mathrm{Foxp}^{+}$regulatory T cells (4) or other regulatory $T$ cell subsets $(5,6)$.

While the available animal models of asthma focus on acute airway inflammatory changes, modeling chronic asthma remains problematic. Prolonging allergen exposure in sensitized animals has been reported to be associated with a disappearance of the inflammatory changes (7-10). Several research groups have been searching for ways to avoid this waning of inflammation to mimic more closely the chronic nature of human asthma (10-13). However, we appreciated this fading away of inflammation as important, since it essentially models the control of unwanted airway inflammation. Up to now, it is not known whether the observed disappearance of inflammation represents a passive phenomenon or an active, immune-mediated process. In addition, the immunologic characteristics of this observation remain unknown.

To address these questions experimentally, we here implement a model in which sensitized mice are exposed to inhaled allergen, establishing Th2-driven airway disease. By prolonging the allergen exposure, we confirm that the allergic airway inflammation disappears completely. We provide the proof of concept that these observations are the consequence of an active, immune-mediated tolerance. We find that, concurrent with eosinophilic airway disease, counter-regulatory mechanisms become activated. Our data suggest that different mechanisms are involved in the inhibition of inflammation upon sustained antigenic challenge. These suppressive mechanisms are antigen dependent and extend to bystander allergens, while they induce a long-term protective memory. We investigate the roles of IL-10, CD $4{ }^{+} \mathrm{CD} 25^{+} \mathrm{Foxp}^{+}$regulatory T cells, DC-T cell interactions, and TLR-4 signaling in this process of disease inhibition, and indicate the differential importance of the inducible costimulator (ICOS), CD28, and programmed death (PD)-1 receptor.

\section{MATERIALS AND METHODS}

\section{Animals}

C57BL/6 mice (males, 6-8 wk old) were purchased from Harlan (Zeist, the Netherlands). IL-10 knockout (KO) mice (C57BL/6-IL10 ${ }^{\mathrm{tm} / \mathrm{Cgn}}$, males, 6-8 wk), the corresponding C57/BL6 wild-type (WT) controls, Toll-like receptor (TLR)-4 KO mice (C57BL/10ScNJ, 6-8 wk), and 
the C57BL/10 WT controls (6-8 wk) were purchased from Jackson Laboratories (Bar Harbor, ME). All experimental procedures were approved by the local ethical committee for animal experiments (Faculty of Medicine and Health Sciences, Ghent University, Ghent, Belgium).

\section{Allergen Exposure Protocols}

Short- and long-term OVA exposure protocols-Protocol 1. To characterize the effects of short- versus long-term allergen exposure in sensitized mice, groups of $8 \mathrm{C} 57 \mathrm{BL} / 6$ mice were sensitized with $10 \mu \mathrm{g}$ OVA (Grade V; Sigma, St. Louis, $\mathrm{MO}$ ) adsorbed to $1 \mathrm{mg} \mathrm{Al}(\mathrm{OH})_{3}$ intraperitoneally on Days 0 and 7. From Day 14 onward, the mice were exposed to aerosolized OVA (1\% wt/vol, Grade III; Sigma) or PBS $30 \mathrm{~min} / \mathrm{d}$, three times per week for 2 and $8 \mathrm{wk}$, respectively (Figure 1, Protocols $1 A$ and $1 B$ ). For analysis, the mice were killed $24 \mathrm{~h}$ after the last exposure.

Specific and bystander immune tolerance: re-immunization and rechallenge protocols-Protocol 2. To analyze the effects of long-term antigen exposure on the immune system, OVA-sensitized C57BL/6 mice $(n=8 /$ group $)$ previously subjected to the long-term OVA challenge protocol were re-sensitized with OVA/alum and re-challenged with OVA aerosols (OVA/OVA-exposed group). Groups of OVA- sensitized but PBS-challenged mice were also re-immunized and rechallenged with either OVA (PBS/OVA-exposed group; positive control) or PBS (PBS/PBS-exposed group; negative control) (Figure 1, Protocol 2A). IL-10 KO mice and TLR-4 KO mice were also subjected to this protocol. For analysis, the mice were sacrificed $24 \mathrm{~h}$ after the last exposure.

In Protocol 2B, OVA sensitized C57BL/6 mice ( $n=8-11 /$ group) subjected to the long-term OVA challenge protocol were re-sensitized and re-challenged with the bystander allergen hen egg lysozyme (HEL; Sigma) (10 $\mu \mathrm{g}$ HEL/alum intyraperitoneally) (OVA/HEL-exposed group). Positive and negative control groups were included (PBS/HELand PBS/PBS-exposed groups, respectively) (Figure 1, Protocol 2B). For analysis, the mice were killed $24 \mathrm{~h}$ after the last exposure.

Memory response protocol-Protocol 3. To analyze whether the immune inhibition upon of long-term antigen exposure has memory characteristics, OVA-sensitized mice ( $n=8$ /group) were subjected to the long-term protocol (8 wk OVA exposure), followed by an 8 -wk resting period (5-10\% of the lifetime expectancy). Next, mice were reimmunized and re-challenged with OVA (Figure 1, Protocol 3) (OVA/ OVA group). Positive and negative control groups were included (PBS/ OVA and PBS/PBS). For analysis, the mice were killed $24 \mathrm{~h}$ after the last exposure.

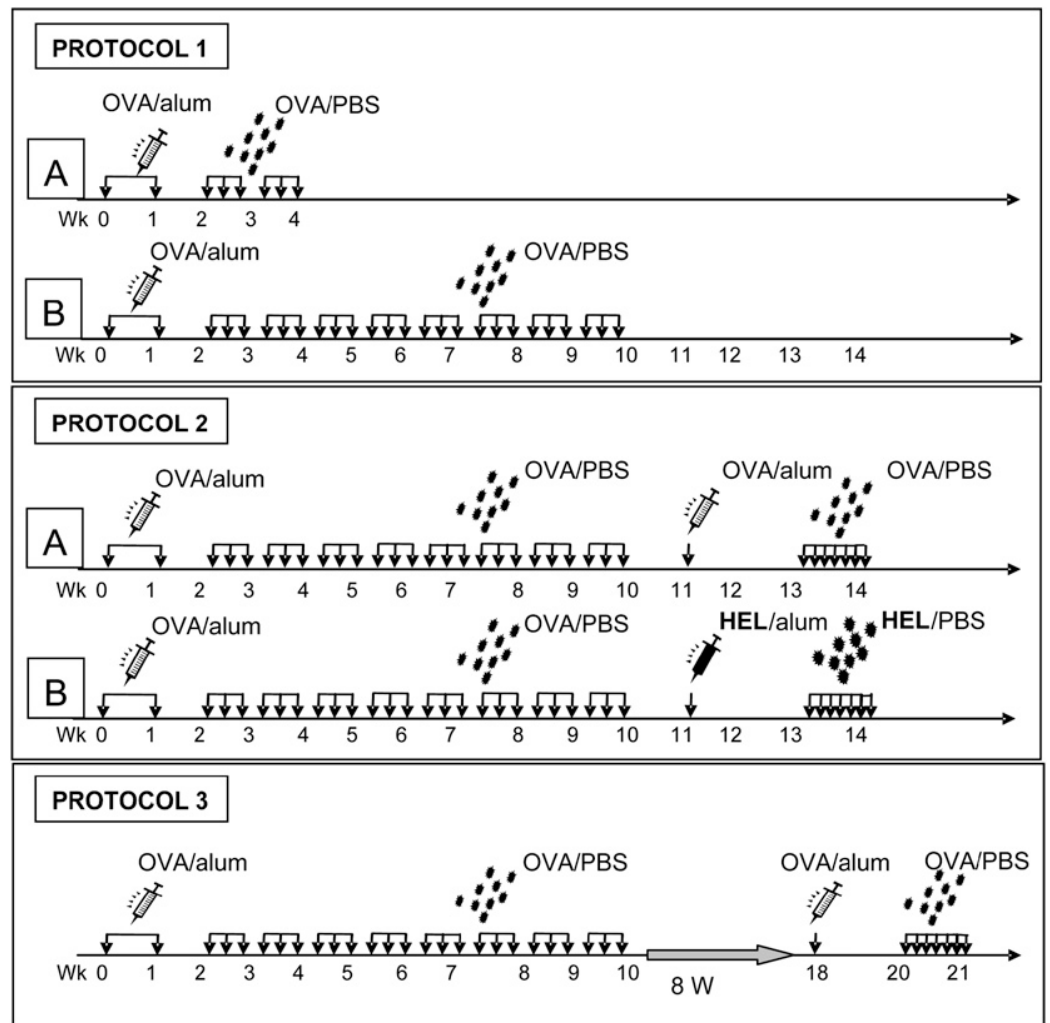

PROTOCOL 4

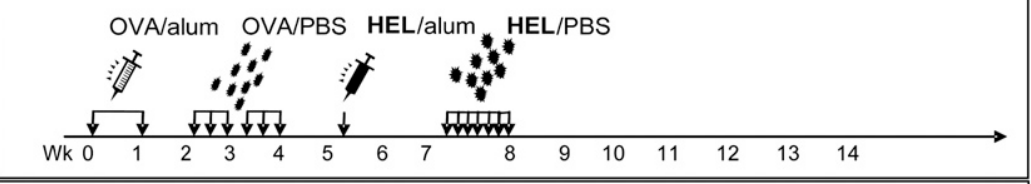

PROTOCOL 5

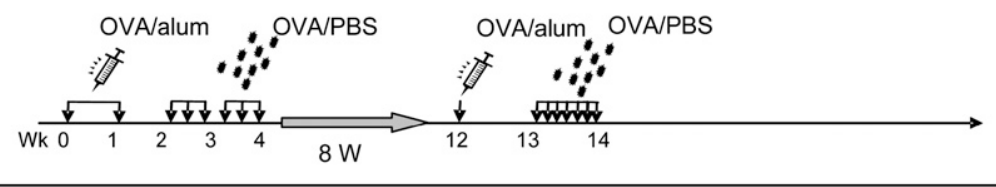

Figure 1. Allergen exposure protocols. Protocol 1. (A) Exposure of OVA sensitized C57BL/6 mice to PBS or OVA aerosols for $2 \mathrm{wk}$. ( $B$ ) Prolonged PBS or OVA aerosol exposure in OVA-sensitized mice ( $8 \mathrm{wk}$ ). Protocol 2. (A) Resensitization with OVA/alum and re-challenge with OVA or PBS aerosols ( $1 \mathrm{wk}$ ) after long-term OVA or PBS aerosol exposure in OVA-sensitized mice. (B) Re-sensitization with the bystander allergen HEL (HEL/alum) and challenge (1 wk) with this secondary allergen or PBS after prolonged OVA or PBS aerosol exposure in OVA-sensitized mice. Proto$\mathrm{col}$ 3. Re-sensitization with OVA/alum and re-challenge with OVA or PBS aerosols (1 wk) after prolonged OVA or PBS aerosol exposure followed by an 8 -wk resting period. Proto$\mathrm{col}$ 4. Re-sensitization (HEL/alum) and challenge with the bystander allergen HEL or PBS after only 2 wk of OVA or PBS aerosol exposure. Protocol 5. Re-sensitization with OVA/alum and re-challenge with OVA or PBS aerosols (1 wk) after only 2 wk of OVA or PBS aerosol exposure followed by an 8-wk resting period. 
Bystander response short protocol-Protocol 4. To analyze whether short-term antigen exposure inherently activates immune inhibitory mechanisms, we shortened the period of OVA exposure from $8 \mathrm{wk}$ down to 2 wk before re-sensitizing and re-challenging ( $n=8$ /group) with HEL (Figure 1, Protocol 3) (OVA/HEL-exposed group). Positive and negative control groups were included (PBS/HEL and PBS/PBS groups). For analysis, the mice were killed $24 \mathrm{~h}$ after the last exposure.

Specific immune tolerance: importance of long-term exposureProtocol 5. In Protocol 5 we examined whether the long-term antigen exposure was necessary to obtain full and persistent disease inhibition. Therefore, four groups of OVA-sensitized (Day 0) C57BL/6 mice ( $n=8 /$ group) were challenged for only 2 wk to either OVA or PBS (Days 14-28), followed by 8 wk without exposure. After re-immunization with OVA (Day 84), the mice were exposed for $1 \mathrm{wk}$ to either OVA or PBS (Days 91-98). Positive and negative control groups were PBS/ OVA and PBS/PBS exposed, respectively, while the OVA/OVAexposed group was the test group (Figure 1, Protocol 5). The OVA/ PBS group represented an additional test group and was included to examine the natural declining of inflammation. For analysis, the mice were killed $24 \mathrm{~h}$ after the last exposure.

\section{Bronchoalveolar Lavage: Cellular Analysis}

Twenty-four hours after the last aerosol exposure, mice were killed with an intraperitoneal pentobarbital injection $(60 \mathrm{mg} / \mathrm{kg}$; Sanofi, Libourne, France). Bronchoalveolar lavage (BAL) fluid was taken as described (14). Briefly, three lavages with $0.3 \mathrm{ml}$ HBSS followed by three lavages with $1 \mathrm{ml}$ HBSS were performed via a tracheal cannula. The BAL fluid of the first three fractions was centrifuged and the supernatant was used for cytokine detection. The cell pellet was then added to the rest of the lavage fluid for cell counts on cytospins (May-Grünwald/Giemsa).

\section{Tissue Processing and Lung Single-Cell Suspension for Flow Cytometric Analysis}

After BAL, lung digest was performed as described previously (15), followed by cell counting and labeling for flow cytometry. Cell counting was performed with a Z2 Beckman-Coulter particle counter (BeckmanCoulter, Ghent, Belgium). Flow cytometric analysis of dendritic cells (DC) and T-lymphocytes on lung single-cell suspensions and on BAL fluid was conducted as defined previously (15-17). Monoclonal antibodies used to identify mouse DC (sub)populations were biotinylated antiCD11c (N418 hybridoma; gift from M. Moser, Brussels Free University, Brussels, Belgium) and phycoerythrin (PE)-conjugated anti-IAb and anti-CD86 (Becton Dickinson BD, Erembodegem, Belgium). Anti-rat $\mathrm{IgG} 2 \mathrm{a}-\mathrm{PE}$ was used for isotype control. DCs were identified based on their low autofluorescence, and high CD11c and IAb expression profiles as described (15). Markers used for mouse T cell subpopulations staining were anti-CD3-APC, -CD4-FITC, -CD4-PercP, -CD25-PE, -CD28-PE, -CTLA-4-PE (BD) and anti-ICOS-PE, -PD-1-PE and -Foxp3-PE (e-Bioscience, San Diego, CA). Isotype controls were PEconjugated anti-rat IgG1, -rat IgG2a,, , -golden Syrian hamster IgG, and -rat IgG2b, and FITC-conjugated anti-rat IgM, bodies were revealed using streptavidin-APC. Before analysis, cells were incubated with 7-amino-actinomycin (7-AAD or Viaprobe; BD) for dead cell exclusion. Foxp3 (FJK-16 s) is a transcription factor and hallmark of $\mathrm{CD}^{+} \mathrm{CD} 25^{+}$regulatory $\mathrm{T}$ cells and requires intracellular staining achieved by cytofix/cytoperm. Flow cytometry data acquisition was performed on a dual laser FACSCalibur flow cytometer running CELLQuest software (BD, Mountain View, CA). FlowJo software (www.Treestar.com) was used for data analysis.

\section{Histology}

After fixation of the left lung with $4 \%$ paraformaldehyde, slices from all left lobes were embedded in paraffin for histology. Sections of $2 \mu \mathrm{m}$ were stained with Congo Red. The slides were coded and the peribronchial (and perivascular) inflammation was graded in a blinded fashion using a reproducible scoring system described elsewhere (18). A value from 0 to 3 was adjudged to each tissue section scored. A value of 0 was given when no inflammation was detectable, a value of 1 for occasional cuffing with inflammatory cells, a value of 2 when most bronchi were surrounded by a thin layer of inflammatory cells ( 1 to 5), and a value of 3 when most bronchi were surrounded by a thick layer of inflammatory cells $(>5)$. As 5-7 tissue sections per mouse were scored, inflam- mation scores could be expressed as a mean value per animal and could be compared between groups.

\section{Lymph Node Cell Cultures}

Lung draining lymph nodes were harvested into tissue culture medium (TCM) containing tubes and digested to obtain a single-cell suspension. Cells were cultured in TCM in a flat-bottom, 96-well plate (BD) with $100 \mu \mathrm{g}$ OVA, at a density of $8 \times 10^{5}$ cells per well. After $5 \mathrm{~d}$ of culture, supernatants were harvested and frozen for cytokine measurements.

\section{IgE and Cytokines}

Total, OVA- and HEL-specific IgE in serum and IL-4, IL-5, IL-13, IFN- $\gamma$, IL-10, thymus and activation regulated chemokine (TARC) in the BAL fluid and supernatant of cultured lymph nodes were measured using ELISA kits (R\&D Systems, Abingdon, UK).

\section{RT-PCR}

Total lung RNA was extracted using the RNeasy Midi kit (Qiagen, Hilden, Germany), with an additional DNase step. Reverse transcription was performed at $48^{\circ} \mathrm{C}$ for 30 min followed by 12 min incubation at $95^{\circ} \mathrm{C}$ for denaturation of RNA-DNA heteroduplexes, and a DNA amplification with 50 cycles of $95^{\circ} \mathrm{C}$ for $15 \mathrm{~s}$ and $60^{\circ} \mathrm{C}$ for $1 \mathrm{~min}$. RTPCR was performed starting from $10 \mathrm{ng}$ of total RNA, using an ABI PRISM 7700 Sequence Detection System (Applied Biosystems, Foster City, CA). IL-13, IFN- $\gamma$, and foxp-3 mRNA relative to hypoxanthine guanine phophoribosyl transferase (hprt) mRNA, was analyzed with the Assays-on-Demand Gene Expression Products (Applied Biosystems).

\section{Statistical Analysis}

Data were analyzed with the statistical packet SPSS 14.0 (SPSS Inc., Chicago, IL). Values are expressed as mean \pm SEM. Groups were compared using the Kruskal-Wallis test for screening significant differences between the groups. When $P<0.05$, Mann-Whitney U-test with Bonferroni's conservative corrections were applied to compare the individual groups.

\section{RESULTS}

\section{Persistent Antigen Exposure Inhibits Th2-Driven Airway Inflammation}

C57BL/6 mice, sensitized and challenged for 2 wk with OVA aerosol (Figure 1, Protocol 1A), had a significant increase in the total amount of leukocytes in BAL fluid as compared with the control mice exposed to PBS aerosols (Figure 2). This was primarily due to the influx of eosinophils, although increases in the number of macrophages and lymphocytes were also present. Histopathology of the lungs showed cuffing of the bronchi with mononuclear cells and eosinophils. This airway inflammation was parallelled with increases in total serum (not shown) and antigen-specific IgE, while in BAL fluid and in supernatant of cultured lymph node cells the Th2 cytokine IL-13 and chemokine TARC were both increased (Figure 2). Next, we challenged these mice for 6 (data not shown) or 8 wk with OVA (Figure 1, Protocol 1B). At these time points, we found that in BAL fluid, eosinophils were absent while the total number of leukocytes had returned to baseline. Although OVA-IgE remained elevated as compared with PBS-challenged mice, histopathology of the lungs showed the complete absence of peribronchial eosinophilic inflammation. OVA-IgE did not, however, differ between the mice challenged with OVA for 2 or $8 \mathrm{wk}(P=$ N.S. $)$. The fading of inflammation was also paralleled with a return to baseline of both IL-13 and TARC, measured in the BAL fluid (Figure 2), as well as on supernatant of cultured lymph node cells (data not shown). IFN- $\gamma$ in these compartments did not differ between the groups (data not shown). 

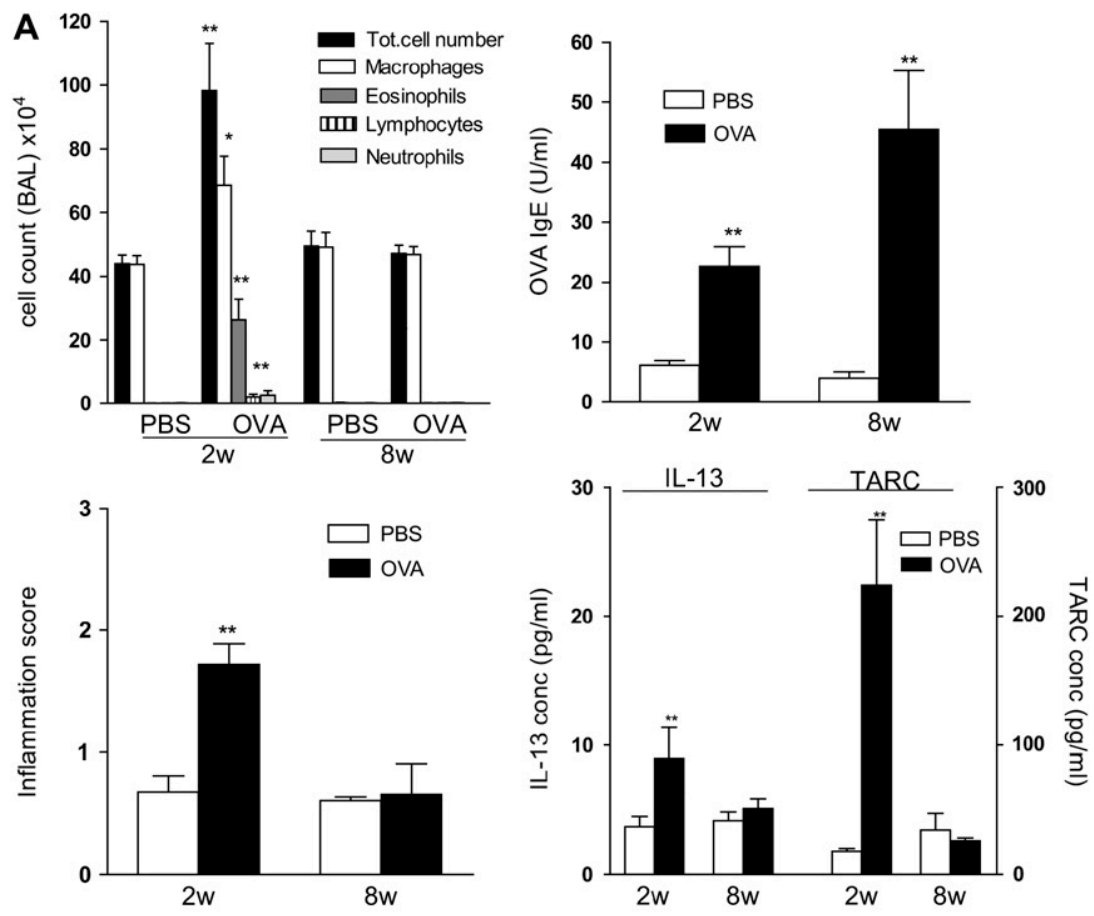

Figure 2. (A) BAL fluid cellular differentials (cytospins), serum OVA-lgE (in $\mathrm{U} / \mathrm{ml}$ ), histology scores, and BAL fluid cytokines in Protocols 1A and 1B. (B) Photomicrographs of Congo Red-stained sections of the airways of OVA-sensitized and -challenged mice (magnification: $\times 100$ ) in Protocol 1A (OVA $2 \mathrm{wk}$ ) and Protocol 1B (OVA 8 wk). Analogous results for IL-13 and TARC were obtained from the supernatant of cultured lymph node cells. $n=8$ /group ${ }^{*} P<0.05,{ }^{*} p<0.005$, OVA versus PBS.

B

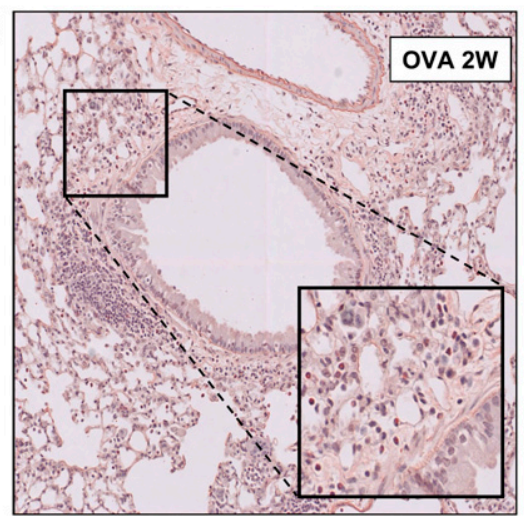

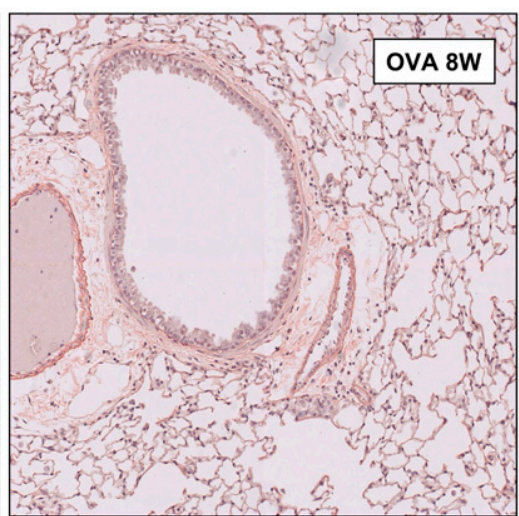

\section{Persistent Antigen Exposure Induces Antigen-Specific and Bystander Immune Tolerance}

To prove that the waning of Th2 airway inflammation upon persistent antigen exposure was the result of an immunemediated tolerance, we had to show resistance of the mice to developing new acquired immune responses upon re-immunization and re-challenge. Therefore, we re-sensitized and shortly re-challenged the mice that had been exposed to OVA aerosols for $8 \mathrm{wk}$ with OVA (OVA/OVA-exposed group) (Figure 1, Protocol 2A). Sensitized mice exposed to 8 wk of PBS were, after the second immunization, re-challenged with either OVA (positive control group; PBS/OVA) or PBS (negative control group; PBS/PBS).

We found that mice subjected to 8 wk of OVA aerosol exposure were completely resistant to develop Th2 skewing. This is underscored by the absence of eosinophils in BAL fluid, while the pulmonary tissue showed no inflammation at all. Specific and total (not shown) serum IgE were suppressed, as were IL-13 and TARC in BAL fluid (Figure 3A). IL-10 levels in BAL fluid were below the detection limit $(<5 \mathrm{pg} / \mathrm{ml})$ in the mice exposed to $8 \mathrm{w}$ of OVA aerosols. This was similar to negative control mice, but contrasted with mice suffering acute inflammation $(12.7 \pm 1.7 \mathrm{pg} / \mathrm{ml})$. Although IL-4 and IL-5 were below the detection limit in BAL fluid, we could detect IL-4, IL-5, IL-10, and IL-13 in the supernatant of cultured (OVA-stimulated) lymph node cells. These cytokines were significantly suppressed in the OVA/OVA-exposed mice as compared with the mice suffering acute allergen-induced airway disease (PBS/OVA group; data not shown).

Next, we measured whether the inhibition of immune responses was also present in the face of nonrelated antigens. When we changed the antigen of the second immunization and re-challenge, and used HEL instead of OVA, we found that the induced immune tolerance had bystander characteristics. The mice, immunized and challenged with OVA for $8 \mathrm{wk}$, were not able to develop Th2-skewing for HEL (OVA/HEL group). No BAL eosinophils, increases in HEL-specific IgE (in Optical Densities, O.D.), airway inflammation, or BAL IL-13 or TARC could be discerned (Figure 3B). This contrasts with mice initially exposed to 8 wk of PBS aerosols. These developed pronounced Th2 responses when immunized and challenged with HEL (i.e., positive control group $\mathrm{PBS} / \mathrm{HEL}$ ). Cytokine patterns similar to those found in the BAL fluid were detected on cultured lymph node cells (not shown). Analysis of lung tissue by RT-PCR also resulted in a similar pattern for IL-13 mRNA, while IFN- $\gamma$ mRNA did not differ between the groups (data not shown). 

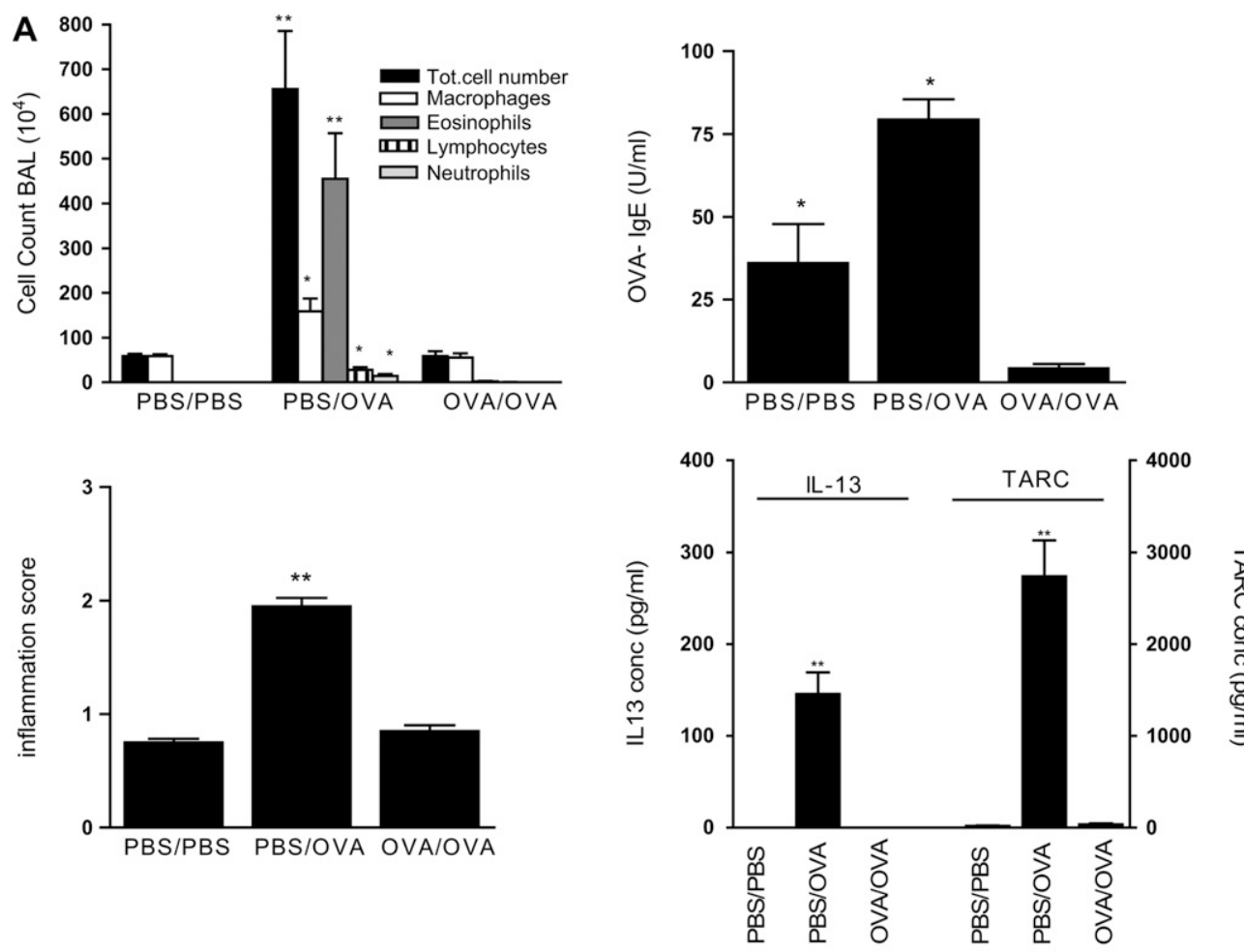

Figure 3. BAL fluid cellular differentials (cytospins), serum OVA-IgE (U/ $\mathrm{ml})$, and HEL-IgE (Optical Densities, O.D.), histology scores and cytokines in BAL fluid (IL-13 and TARC) in Proto-
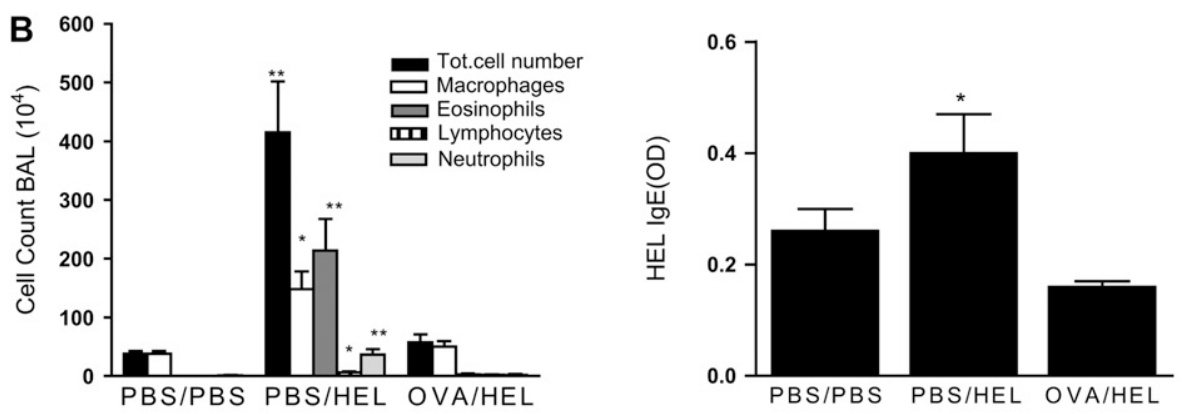
col 2A $(A)$ and Protocol 2B $(B) . n=$ 8-11/group; ${ }^{*} P<0.05,{ }^{* *} P<0.005$ versus OVA/OVA or OVA/HEL.
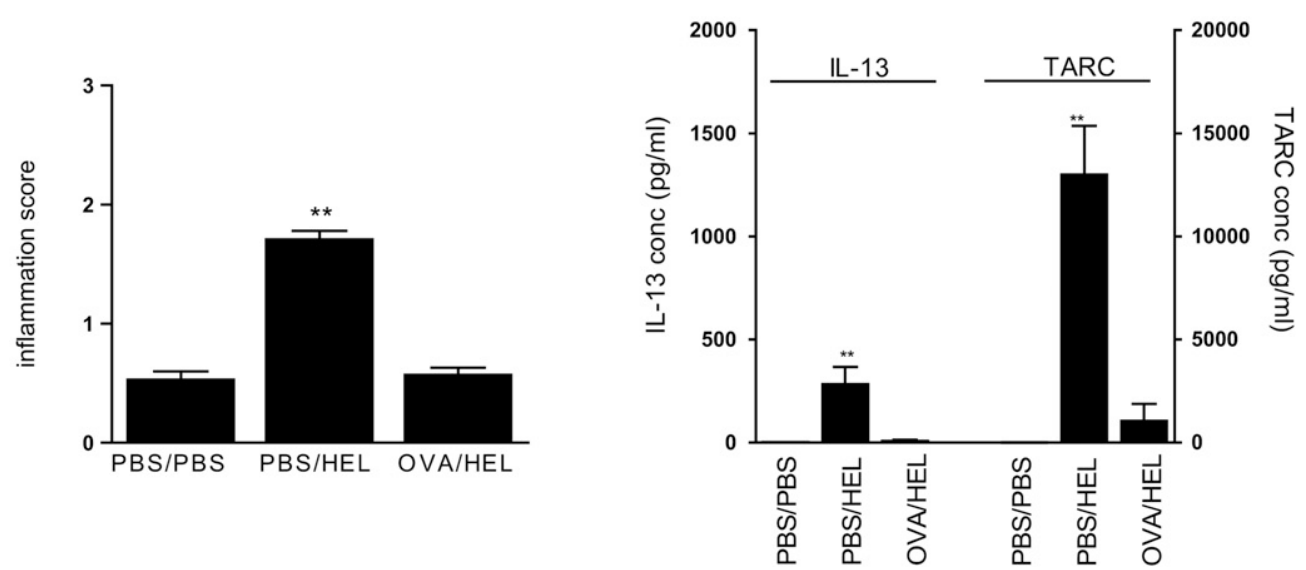

Alterations in DC-T Cell Communication Are Associated with the Inhibition of Disease after Eosinophilic Airway Inflammation

As a next step, we investigated the role of the $\mathrm{CD} 4{ }^{+} \mathrm{CD} 25^{+} \mathrm{Foxp}^{+}$T-regulatory cells and co-stimulatory molecules on DC and T cells (Figure 1, Protocol 2). We chose to analyze the expression of ICOS and PD-1 on T cells and the presence of Foxp $3^{+}$in $\mathrm{CD} 4^{+} \mathrm{CD} 25^{+} \mathrm{T}$ cells because these markers have been implicated in the induction of tolerance. In addition, we evaluated the DC-T cell communication by examining the presence of CD80/CD86 on DC and of CD28 on T cells. The $\mathrm{CD}^{+}{ }^{+}$lung $\mathrm{T}$ cells from mice suffering acute $\mathrm{Th} 2$ airway disease (PBS/OVA exposed) expressed more CD28 and ICOS as compared with the negative control mice (PBS/PBS exposed; Figure 4A). This was paralleled by an increase in the number of DC in both BAL fluid and lung tissue (Figure 4B). In addition, 

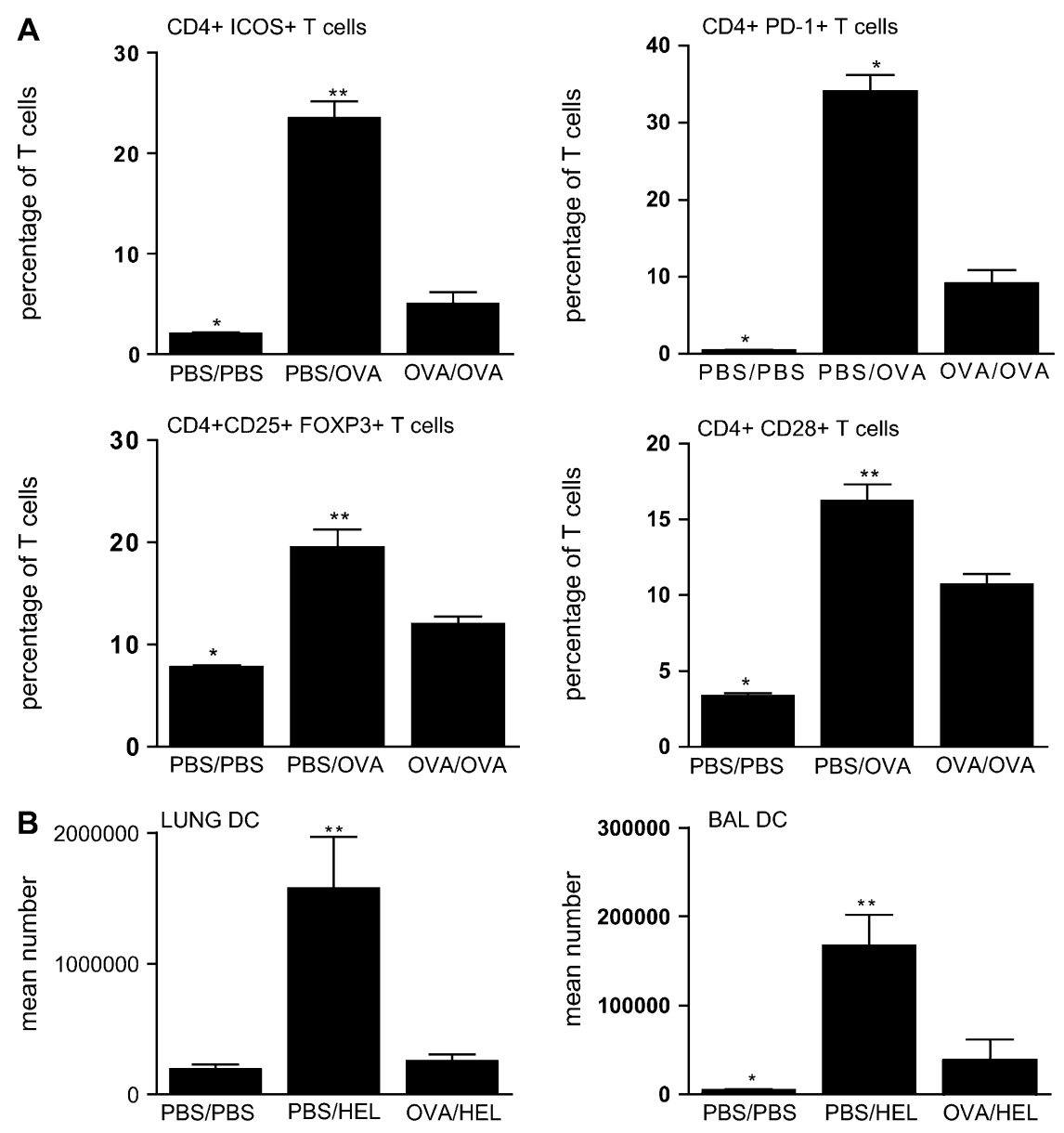

Figure 4. Flow cytometric analysis of the expression of co-stimulatory molecules on lung $\mathrm{CD}^{+}{ }^{+} \mathrm{T}$ cells in Protocol 2A, as percentage of double-positive cells within the $\mathrm{T}$ cell population $(A)$. Flow cytometric analysis of BAL fluid and lung DC number and maturation status (percentage of $\mathrm{CD} 86$ and $\mathrm{MHClI}$ ) of pulmonary DC in Protocol 2B (B). $n=8$ /group; ${ }^{*} P<0.05,{ }^{* *} P<0.005$ versus OVA/OVA or OVA/ HEL.
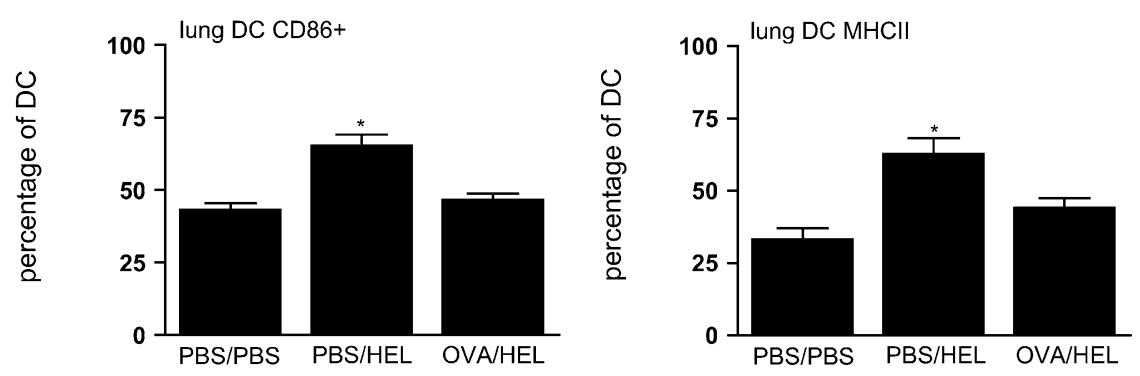

a more mature DC phenotype with an increased expression of MHC class II (MHCII) and CD80/86 in both tissue compartments was found (Figure 4B). Intriguingly, during acute inflammation, significant increases were found in the percentage of $\mathrm{CD}^{+} \mathrm{T}$ cells expressing PD- 1 as well as in the mRNA expression of Foxp3 (data not shown), and in the number of $\mathrm{CD} 4{ }^{+} \mathrm{CD} 25^{+} \mathrm{Foxp}^{+}$cells as compared with the negative control mice (Figure 4A).

In contrast, the tolerant mice chronically exposed to OVA had a marked suppression of CD28 and ICOS expression on the $\mathrm{CD} 4^{+} \mathrm{T}$ cells as compared with the mice suffering acute disease (PBS/OVA exposed), although the expression of these costimulatory molecules was still higher as compared with the negative control mice (PBS/PBS exposed; Figure 4A). The number of BAL fluid and lung DC was reduced in these tolerant mice, while their maturation status (CD80/86-MHCII expression) was significantly inhibited when compared with the mice suffering acute disease (Figure 4B). Numbers and phenotype of DC in the tolerant mice did even not significantly differ from negative control animals. Remarkably, in the tolerant mice, there was less Foxp3 mRNA (not shown), and a significantly reduced percentage of $\mathrm{CD}^{+}{ }^{+} \mathrm{CD} 25^{+}$Foxp $3^{+}$cells and $\mathrm{PD}-1^{+} \mathrm{CD} 4^{+} \mathrm{T}$ cells as compared with the mice suffering acute airway disease (Figure 4A). While the percentage of these cells was still higher than in negative control mice, their absolute numbers in did not significantly differ from negative control mice (not shown).

\section{The Protection upon Persistent Exposure Has a Long-Lasting Immune Memory}

Next, we verified whether the observed resistance to develop Th2 skewing was only a temporary or long-lasting phenomenon. Therefore, in the mice that had been exposed to 8 wk of OVA, a time-out of another $8 \mathrm{wk}$ was introduced before Th2 renewal was attempted (Figure 1, Protocol 3). Thus, we exposed mice to long-term OVA aerosols, and subsequently rested them for a period of $8 \mathrm{wk}$. We then re-immunized and re-challenged them with OVA (OVA/OVA). Our results showed that the mice presented with a complete protection against Th2 skewing: no 
eosinophils or increases in other inflammatory cells could be found in the BAL fluid or around the airways (Figure 5). In line with these results, Th2 cytokines in BAL (Figure 5A) and in supernatant of cultured lymph node cells (data not shown) correspond with the baseline levels found in mice that had never been challenged (PBS/PBS) and were significantly lower than in mice suffering acute Th2 skewing (PBS/OVA). The production of serum OVA-specific and total IgE (not shown) was inhibited in the OVA/OVA-exposed mice (Figure 5A). The latter also had significantly lower percentages of lung $\mathrm{CD} 4^{+} \mathrm{CD} 25^{+} \mathrm{Foxp}^{+}$, $\mathrm{CD} 4^{+} \mathrm{PD}-1^{+} \mathrm{T}$ cells, and $\mathrm{CD} 4^{+} \mathrm{CD} 28^{+}$and $\mathrm{CD}^{+}{ }^{+} \mathrm{ICOS}^{+}$cells
(Figure 5B) when compared with the positive control mice (PBS/ OVA-exposed).

\section{During Eosinophilic Inflammation, the Counter-Regulatory Mechanisms Are Functionally Characterized by Immune Inhibition}

After the observation that concurrent with acute eosinophilic inflammation, increases in $\mathrm{CD} 4{ }^{+} \mathrm{CD} 25^{+} \mathrm{Foxp} 3^{+} \mathrm{T}$ cells (Protocols 2 and 3) were found, we investigated whether parameters of disease inhibition could be demonstrated at a functional level in the period just after the induction of acute airway disease.
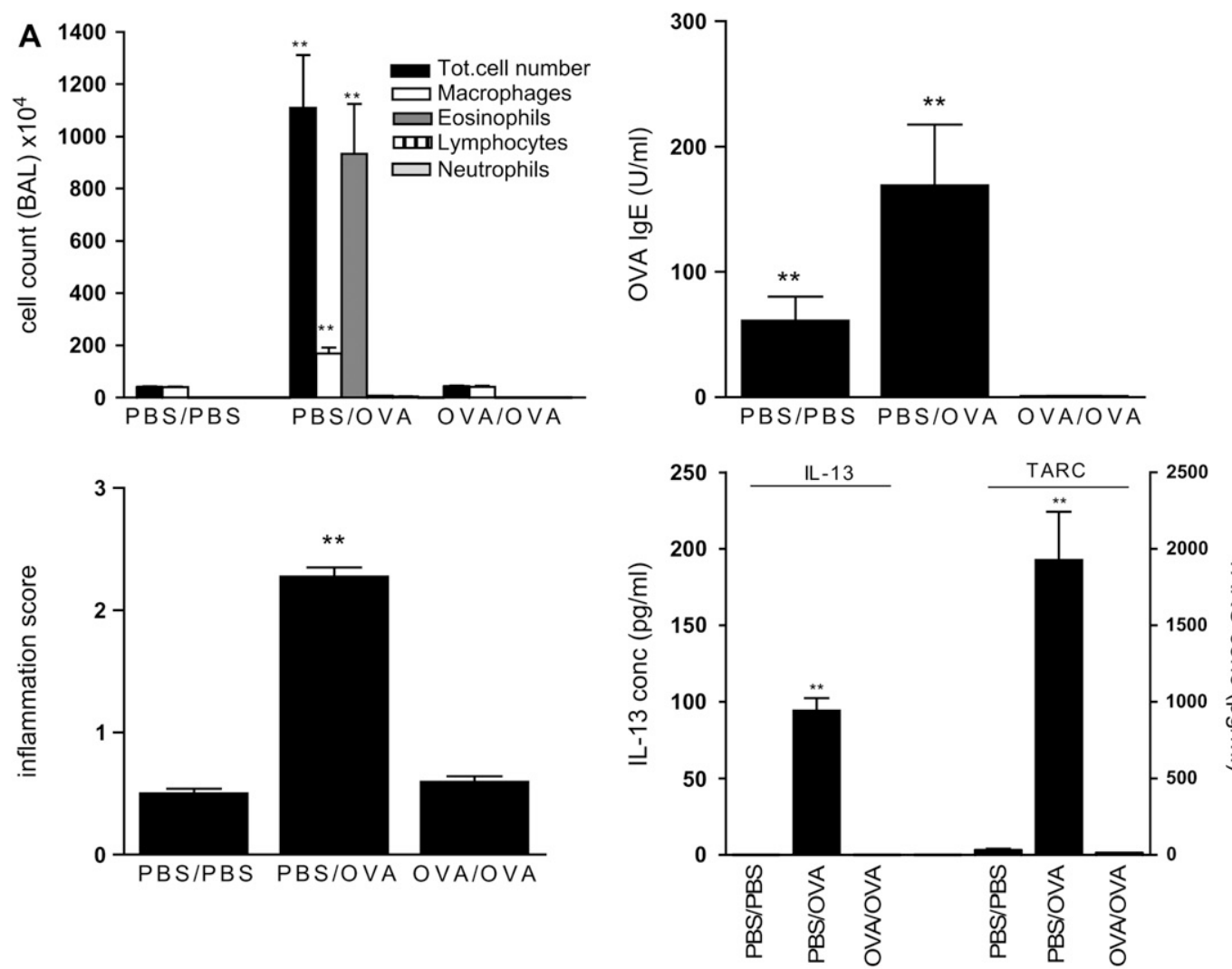

Figure 5. BAL fluid cellular differentials (cytospins), serum OVA-lgE $(\mathrm{U} / \mathrm{ml})$, histology scores, and BAL fluid cytokines in Protocol 3 (memory response protocol) $(A)$. Analogous results for IL-13 and TARC were obtained from the supernatant of cultured lymph node cells $(B)$. Flow cytometric analysis of the expression of costimulatory molecules on lung $\mathrm{CD}^{+}{ }^{+} \mathrm{T}$ cells in Protocol 4, as
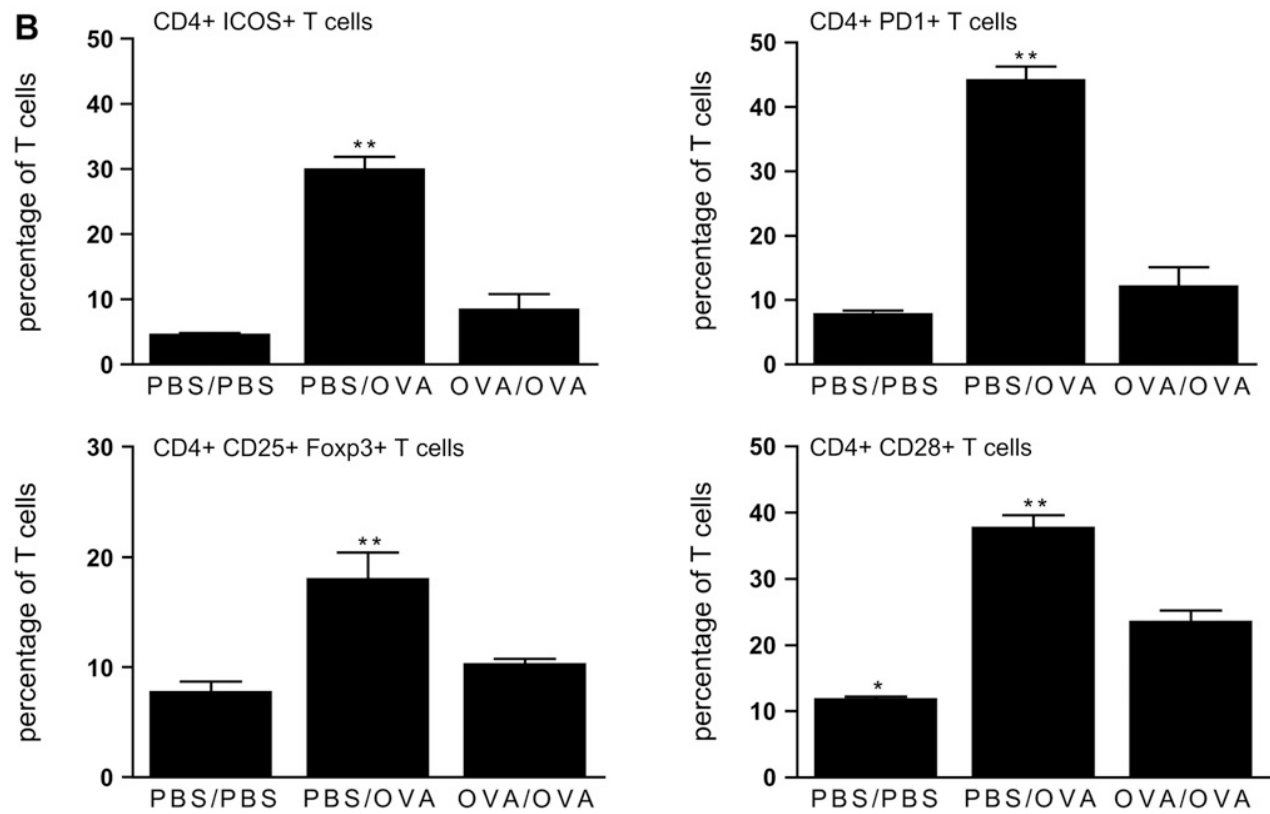
percentage of double-positive cells within the $T$ cell population. $n=8 /$ group; ${ }^{*} P<0.05$, $\star * p<0.005$ versus OVA/OVA. 
Therefore, a new experiment was performed in which mice, with acute eosinophilic airway disease were stimulated to develop a new immune response in the face of a nonrelated antigen, in casu HEL (Figure 1, Protocol 4). We hypothesized that mice suffering recently induced Th2 skewing would already have functional characteristics of disease inhibition. Indeed, sensitized mice exposed to OVA for only 2 wk and re-immunized and exposed to HEL (OVA/HEL) displayed partial inhibition of Th2 responses as compared with mice that suffered full-blown inflammation (PBS/HEL). The development of eosinophilia in BAL fluid, HEL-specific serum IgE, pulmonary inflammation, and Th2 cytokine production were all significantly inhibited (Figure 6). TARC was also inhibited in these mice, but was still higher as compared with the negative control group (PBS/PBS).

The Counter-Regulatory Mechanisms Activated during Acute Allergic Airway Inflammation Are Not Sufficient to Induce Full and Persistent Disease Inhibition

Faced with the facts that in sensitized mice, long-term antigen exposure can induce tolerance mechanisms resulting in a full (Protocol 2) and persistent (Protocol 3) disease control on the one hand, and that sensitized mice suffering acute Th2-mediated inflammation have discernible and functionally active antiinflammatory mechanisms (Protocol 4) on the other hand, it remained to be established if the long-term exposure to antigen was necessary to obtain a full and persistent inhibition of disease. This hypothesis was tested in Protocol 5 (Figure 1, Protocol 5). In this protocol, we included an additional group (OVA/PBSexposed) to evaluate the natural declining of inflammation.

We found that exposing sensitized mice to OVA for only $2 \mathrm{wk}$, followed by a resting period (6-8 wk) and then followed by a re-sensitization and re-challenge episode, resulted in a significant reappearance of eosinophilic airway disease in the OVA/OVA- exposed test group. This was evidenced by increased BAL fluid cell numbers and the reappearance of BAL fluid eosinophils (Figure 7A), as well as by the re-appearance of eosinophilic pulmonary inflammation. Although we were not able to detect increases in IL-13 and IgE, the chemokine TARC was increased in the OVA/OVA group as compared with the negative control group (Figure 7A). Nevertheless, the magnitude of the eosinophilic airway inflammation (absolute numbers of BAL fluid eosinophils, the pulmonary inflammation; TARC and IL-13 concentration) was still significantly lower in the OVA/OVA group as compared with the positive control group (PBS/OVAexposed). The additional group ("OVA/PBS") investigating the natural declining of inflammation shows that inflammation has already waned at the moment of re-sensitization and rechallenge. The patterns of expression of CD28 and to a lesser extent the expression patterns of ICOS and PD-1 on lung T cells, as well as the percentage of $\mathrm{CD}^{+}{ }^{+} \mathrm{CD} 25^{+} \mathrm{Foxp}^{+}$regulatory $\mathrm{T}$ cells in the lung, are consistent with the patterns previously observed during acute inflammation, as was the case for the number of DC (not shown). In summary, the data of Protocol 5 show that long-term OVA aerosol exposure is needed for the development of full and persistent mucosal tolerance.

\section{The inhibition of Disease Is Not Mediated through TLR-4 Signaling}

In a final set of experiments, we tested whether LPS signaling through the TLR-4 receptor was involved, since the TLR-4 receptor represents a major pathway for endotoxin to exert its immunologic effects. First, we measured the LPS contamination in the OVA used for nebulization (grade III; Sigma) by limulus amoebocyte lysate (LAL) assay. The OVA used contained 5.82

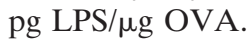
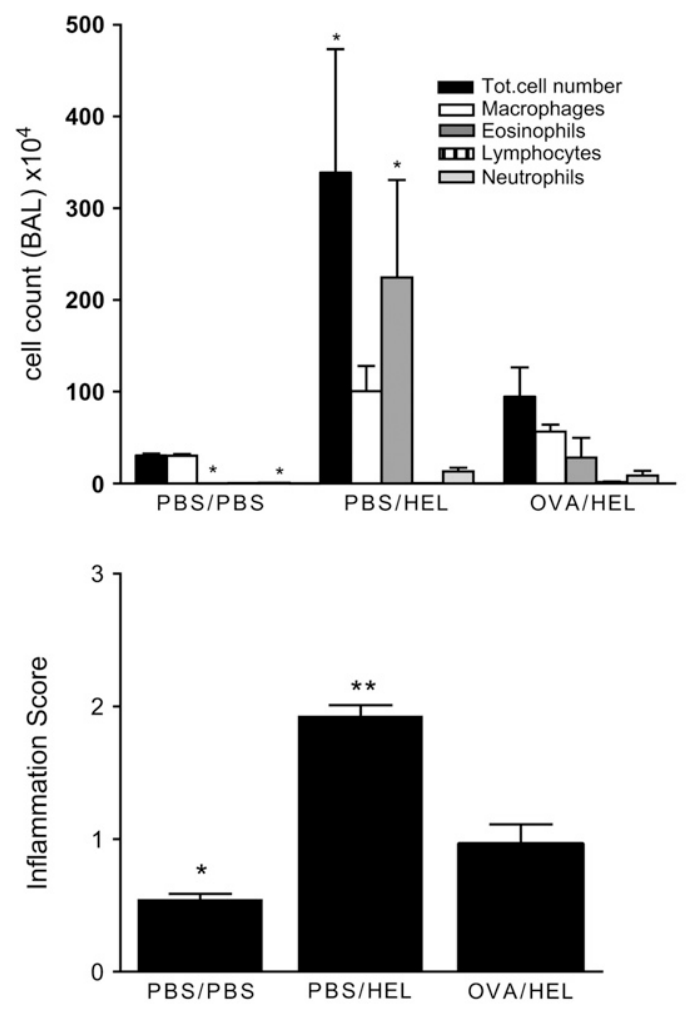
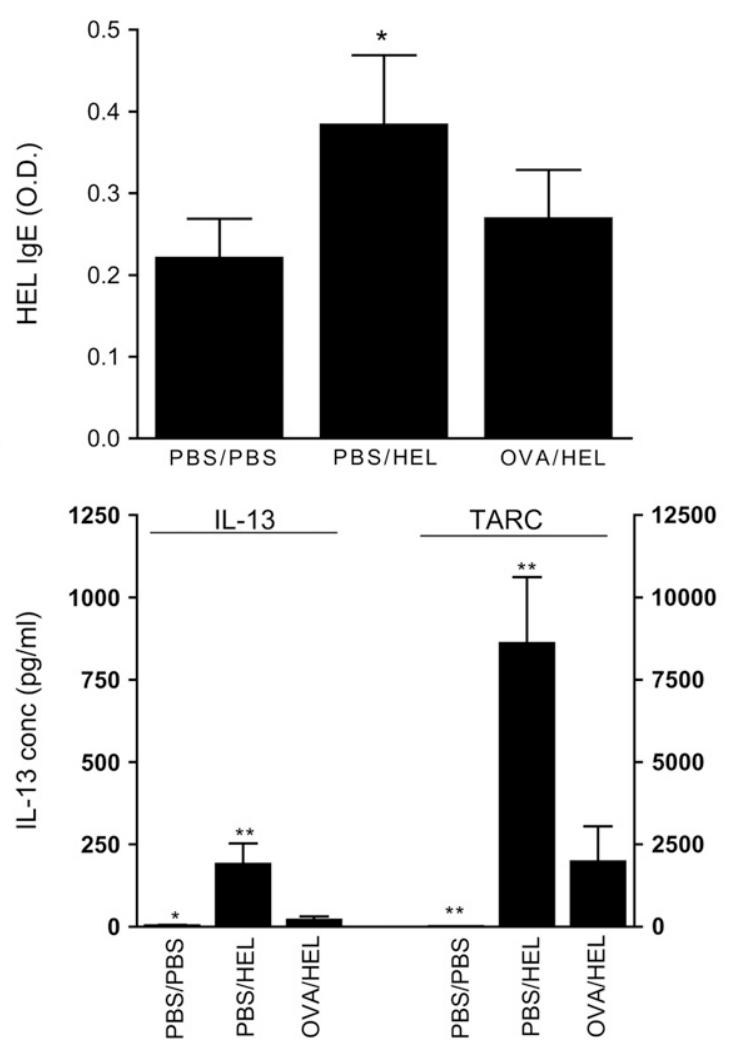

Figure 6. BAL fluid cellular differentials (cytospins), serum HEL-IgE (O.D.), histology scores, and BAL fluid cytokines in Protocol 4 (bystander response short protocol). $n=8 /$ group; ${ }^{*} P<0.05$, $* * P<0.005$ versus OVA/ HEL. 

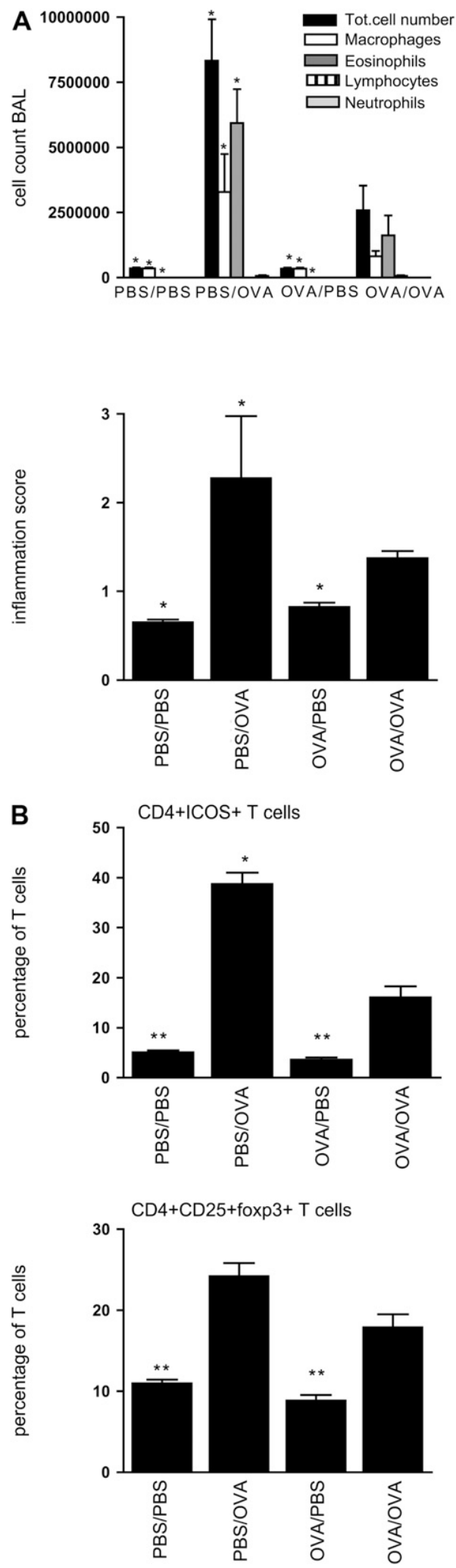
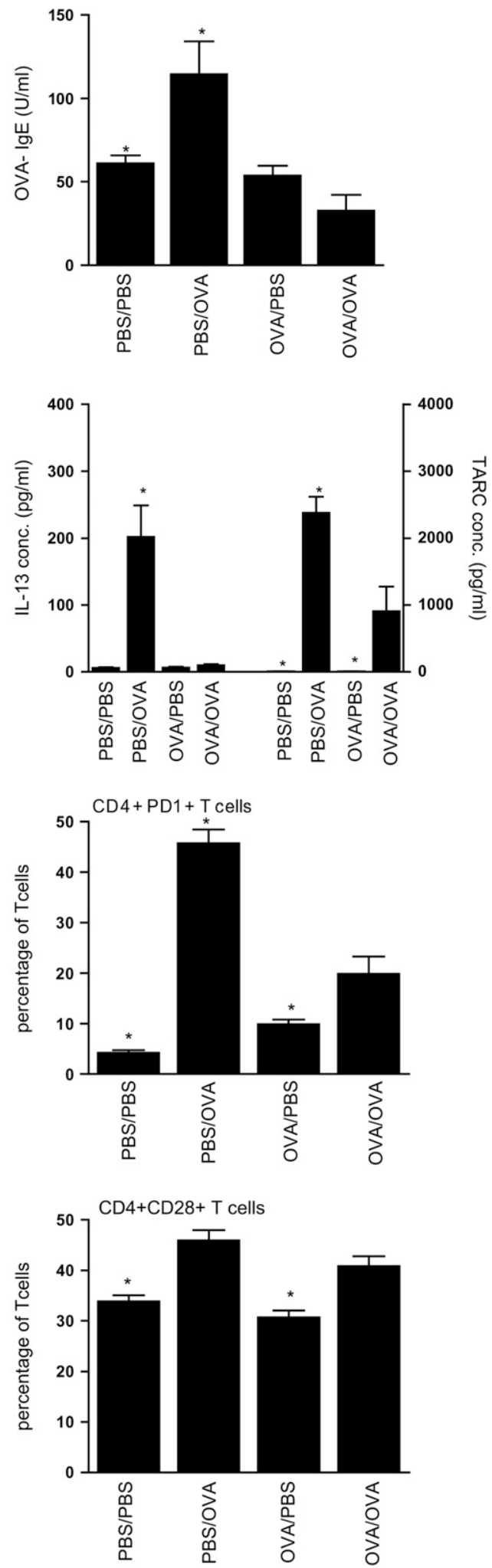

Figure 7. A.BAL fluid cellular differentials (cytospins), serum OVA-lgE (Units/ml), histology scores and BAL fluid cytokines in Protocol $5(A)$. Analogous results for IL-13 and TARC were obtained from the supernatant of cultured lymph node cells. (B) Flow cytometric analysis of the expression of co-stimulatory molecules on lung $\mathrm{CD}^{+} \mathrm{T}$ cells in Protocol 5, as percentage of double-positive cells within the $T$ cell population (B). $n=8 /$ group; ${ }^{*} P<0.05$, $* * P<0.005$ versus OVA/OVA.
Next, we used C57/BL10 TLR-4 KO mice and the corresponding C57/BL10 WT mice in Protocol 2A shown in Figure 1. Our data indicated that in both WT and in TLR-4 KO mice, longterm exposure to OVA induced a state of disease inhibition after the eosinophilic airway inflammation. This was again evident from the absence of eosinophils in BAL fluid, of airway inflammation, serum IgE and the Th-2 cytokine IL-13, and the chemokine TARC (Figure 8). The inhibition of disease was comparable between the two strains and was complete, as these parameters corresponded with their baseline levels (PBS/PBS).

\section{DISCUSSION}

The data presented here support the hypothesis that firm and long-lasting control of allergen-induced airway inflammation by inducing immune tolerance is feasible. In sensitized mice 

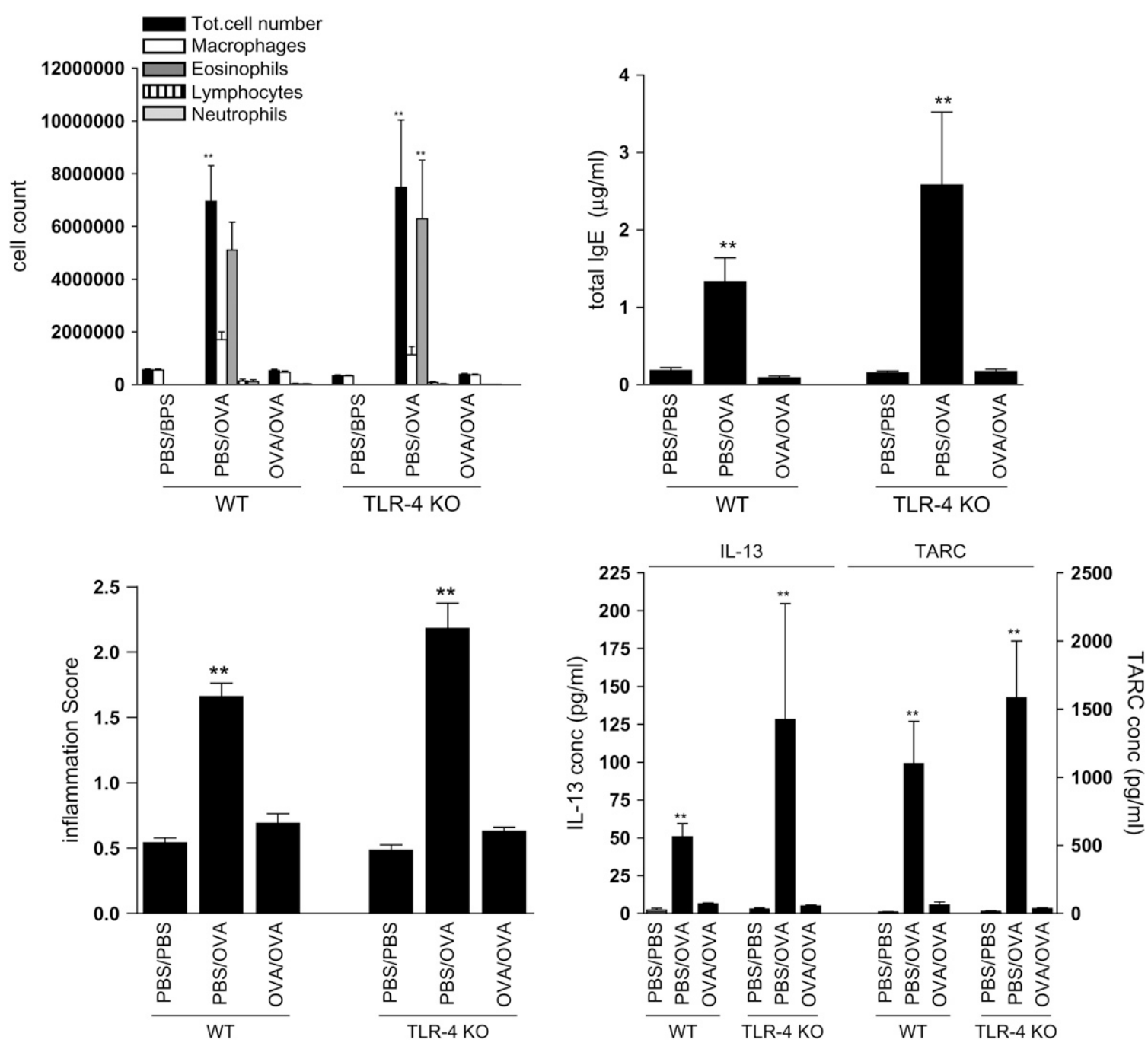

Figure 8. BAL fluid cellular differentials (cytospins), serum total $\operatorname{lgE}(\mu \mathrm{g} / \mathrm{ml})$, histology scores and BAL fluid cytokines in TLR-4 KO mice subjected to Protocol 2A. Analogous results for IL-13 and TARC were obtained from the supernatant of cultured lymph node cells. $n=7 / \mathrm{group} ;{ }^{* *} P<0.005$ versus OVA/OVA.

exposed to OVA aerosols for 8 wk ("long-term" or "chronic"), marked alterations in the DC-T cell phenotype and co-stimulatory molecule expression were observed. A reduced expression of ICOS and CD28 on the CD $4^{+}$T cells and of CD80/86 and MHCII on the DC was found compared with active inflammation. In addition, we showed that the mechanisms involved in long-term disease control were not characterized by increases in $\mathrm{CD} 4{ }^{+} \mathrm{CD} 25^{+} \mathrm{Foxp}^{+}$T-regulatory cells, IL-10 secretion or PD-1. On the contrary, these markers were even down-regulated. This differs from the counter-regulatory mechanisms activated early on during an acute inflammatory process or upon preventive inhalational or oral tolerance induction $(4,5)$.

Although discontinuous administration of antigens such as OVA has been reported to result in a persistent moderate airway inflammation (7), and although other studies using house dust mite (11) or Aspergillus fumigatus (19) extracts have documented the establishment of chronic eosinophilic airway inflammation, a number of reports, as well as our current data, have indicated the possibility to obtain a full control of airway inflammation upon continued antigen exposure (7-9). The disappearance of the inflammation in our model was not only evident in the BAL fluid, but also in the lung tissue and is underscored by the waning of the Th2 cytokines and chemokines such as IL-13 and TARC. The mechanisms underlying this observation are unknown, although of potential relevance to control airway inflammation in patients with asthma.

First, we hypothesized that the resolution of inflammation was the consequence of an active, immune-mediated mechanism. This was tested by re-immunizing and by re-challenging the mice in which airway inflammation had disappeared, after 8 wk of antigen exposure. Indeed, a firm protection against Th2 skewing with an inability to mount eosinophilic disease, $\mathrm{IgE}$ and $\mathrm{Th} 2$ cytokines and chemokines was found. By definition, these observations show the induction of immune tolerance, the latter being the absence of an acquired immune response in face of an antigen for which the immune system has the capability to respond (20). These mice thus behaved as being in a condition of disease inhibition after eosinophilic airway inflammation.

Second, we tested whether several mediators involved in tolerance induction upon feeding or inhaling a protein antigen before sensitization were involved $(4,6,21)$. Prominent roles of $\mathrm{CD} 4{ }^{+} \mathrm{CD} 25^{+} \mathrm{Foxp}^{+}$T-regulatory cells $(4,21)$, tolerogenic DC (6), the immunomodulatory cytokine IL-10 (22), and even ICOS (5) have been indicated. The role of ICOS in this context is dual, 
since ICOS-ICOSL coupling plays a role in both the induction of Th2 diseases (23) and in T-regulatory cell-mediated tolerance $(5,24,25)$. The inhibitory molecule PD-1 has also been implicated in peripheral tolerance induction $(26,27)$. In mice made tolerant by long-term OVA aerosols, we found, after re-immunization and re-challenge, a significant reduction in both BAL fluid and pulmonary DC compared with mice suffering acute eosinophilic airway disease. A decrease in "myeloid" DC, as identified here (15), has been causally linked to the waning of inflammation after repeated allergen exposure (28), possibly by altering the ratio with the tolerogenic "plasmacytoid" DC (29). The percentage of lung and BAL fluid DC expressing CD80/86 was also significantly reduced. First, this altered DC maturation status suggests that the inhibition of disease cannot simply be explained by anergic $\mathrm{T}$ cells, since anergy is a state of nonresponsiveness of the T cells despite optimal conditions of stimulation. Second, the co-stimulatory molecules CD80/86 have been implicated in ICOS expression (30). Indeed, we found on the $\mathrm{CD}^{+} \mathrm{T}$ cells a significant reduction in the expression of both ICOS and CD28, the latter also implicated in ICOS expression (30). Taken together, these data indicate that these mice have acquired resistance to DC maturation and subsequent $\mathrm{T}$ cell activation, which explains why no adaptive immune response could be mounted.

IL-10 secretion in the BAL fluid and supernatant of cultured lymph node cells of the chronically challenged mice was decreased upon re-sensitization and re-challenge. Although there is one study that reported IL-10-independent inhalational tolerance (31), the data we obtained from an experiment using IL-10 KO mice did not allow a clear interpretation (Protocol 2B; data not shown). Therefore, the possible role of IL-10 remains to be established in this model of tolerance induction. Intriguingly, we detected a decrease in the percentage and absolute numbers of $\mathrm{CD} 4{ }^{+} \mathrm{CD} 25^{+}$foxp $3^{+}$T-regulatory cells in the lungs of the chronically challenged mice compared with the mice suffering acute eosinophilic airway disease. The absolute number of this $\mathrm{T}$ cell subset did not differ from negative control. These data suggest that that the number of these cells is not important in the inhibition of disease after long-term OVA challenge. However, with our data, we cannot formally exclude an enhanced regulatory activity of these cells to explain the observed antiinflammatory effect.

One could propose that the observations of full disease inhibition and the reduction of the co-stimulatory molecule expression on $\mathrm{DC}$ and $\mathrm{CD}^{+}{ }^{+} \mathrm{T}$ cells upon chronic antigen exposure are the consequence of a temporary exhaustion of the immune system. By scheduling an 8-wk resting period after chronic exposure and before re-immunization and re-challenge, we could show that the status of disease inhibition after the eosinophilic airway inflammation had memory characteristics. This indicates that the immune system had acquired a very efficient protective memory, persistently inhibiting new adaptive immune responses for a period covering 5-10\% of the average life expectancy of a mouse. Even after an 8-wk resting period without antigen challenge, the number of $\mathrm{CD} 4{ }^{+} \mathrm{CD} 25^{+} \mathrm{Foxp} 3^{+}$remained low, as did the expression of CD28 and ICOS.

These observations in tolerant mice were thus in contrast with mice suffering acute eosinophilic inflammation, in which an up-regulation of $\mathrm{CD}^{+} \mathrm{CD} 25^{+} \mathrm{Foxp}^{+} \mathrm{T}$ cells along with an increased expression of IL-10 and PD-1 was seen, indicating that these anti-inflammatory mechanisms became activated concurrent with the eosinophilic inflammation. The apparent duality in the presence of both pro-inflammatory and anti-inflammatory mechanisms led us to test functionally whether mice suffering from eosinophilic airway inflammation had simultaneous characteristics of immune inhibition. We found that a secondary immunization and challenge with another antigen immediately after short-term exposure ( $2 \mathrm{wk}$ ) to the primary antigen OVA, did not result in overt airway disease as compared with control mice, which previously did not suffer from eosinophilic airway disease (Protocol 4). An inhibition of bystander IgE and of airway eosinophilia by $>90 \%$ shows that anti-inflammatory mechanisms were already engaged, despite the recently induced eosinophilic airway disease, and illustrates that tolerogenic mechanisms were active even during eosinophilic airway disease. These antiinflammatory mechanisms, active during eosinophilic inflammation, were nevertheless not sufficient to induce a full and persistent inhibition of disease upon subsequent re-immunization and re-challenge (Protocols 3 and 5). In other words, only chronic exposure to antigen ( $8 \mathrm{wk}$ ) was able to induce a full and persistent waning of inflammation.

It was also possible that the inhibition to develop inflammatory responses was codetermined by exogenous factors such as ubiquitously present, contaminating endotoxin. This hypothesis made sense from a theoretical point of view, since there is epidemiologic evidence implicating endotoxin as a protective factor against asthma (32). In a mouse model, it has been shown that high doses of endotoxin $(10 \mu \mathrm{g} / \mathrm{d})$ can inhibit eosinophilic airway inflammation, although this was accompanied by a shift toward a Th1 response, as identified by IFN- $\gamma$ and neutrophilic pneumonitis (33). Moreover, in a mouse model of prolonged OVA challenge, endotoxin has been reported to down-regulate allergic airway inflammation through TLR-4 signaling (34). Others nevertheless reported inhalational tolerance that was not mediated by endotoxin (35). Our data clearly show that signaling through the TLR-4 receptor did not critically mediate the disease inhibition after eosinophilic airway inflammation, since we observed very similar protective effects in both TLR-4 KO and WT mice.

In summary, our results indicate that the resolution of Th2driven airway disease upon persistent antigen exposure is explained by the induction of immune tolerance. This immune tolerance is antigen dependent and extends to bystander allergens. It is characterized by a firm and long-lasting inhibition of DC maturation and of the co-stimulatory molecules CD28 and ICOS on T cells. Moreover, no up-regulation of IL-10, PD-1, or $\mathrm{CD} 4{ }^{+} \mathrm{CD} 25^{+} \mathrm{Foxp}^{+}$T-regulatory cells was discovered. LPS signaling through the TLR-4 receptor was not involved in the induction of inhalational tolerance. Our data suggest that the mechanisms of the disease inhibition after eosinophilic airway inflammation may differ from the anti-inflammatory mechanisms that become activated during acute eosinophilic airway disease. Further elucidation of these mechanisms could reveal important players implicated in controlling allergic airway inflammation.

Acknowledgments: The authors are indebted to E. Castrique, M.M. Mouton, A. Neessen, I. De Borle, C. Snauwaert, and K. De Saedeleer for the technical assistance. They thank Prof. Dr. J. Grooten and Dr. G. Pynaert (Department of Molecular Biomedical Research, Molecular Immunology Unit, Flanders Interuniversity Institute for Biotechnology, Ghent University, Belgium) for the help in dosing lipopolysaccharide.

\section{References}

1. Tattersfield AE, Knox AJ, Britton JR, Hall IP. Asthma. Lancet 2002; 360:1313-1322.

2. Kips JC, Anderson GP, Fredberg JJ, Herz U, Inman MD, Jordana M, Kemeny DM, Lotvall J, Pauwels RA, Plopper CG, et al. Murine models of asthma. Eur Respir J 2003;22:374-382.

3. Tournoy KG, Hove C, Grooten J, Moerloose K, Brusselle GG, Joos GF. Animal models of allergen-induced tolerance in asthma: are T-regulatory- 1 cells ( Tr- 1 ) the solution for T-helper- 2 cells (Th-2) in asthma? Clin Exp Allergy 2006;36:8-20.

4. Ostroukhova M, Seguin-Devaux C, Oriss TB, Dixon-McCarthy B, Yang L, Ameredes BT, Corcoran TE, Ray A. Tolerance induced by inhaled antigen involves CD4(+) T cells expressing membrane-bound TGFbeta and FOXP3. J Clin Invest 2004;114:28-38. 
5. Akbari O, Freeman GJ, Meyer EH, Greenfield EA, Chang TT, Sharpe AH, Berry G, DeKruyff RH, Umetsu DT. Antigen-specific regulatory $\mathrm{T}$ cells develop via the ICOS-ICOS-ligand pathway and inhibit allergen-induced airway hyperreactivity. Nat Med 2002;8:1024-1032.

6. Akbari O, DeKruyff RH, Umetsu DT. Pulmonary dendritic cells producing IL-10 mediate tolerance induced by respiratory exposure to antigen. Nat Immunol 2001;2:725-731.

7. Schramm CM, Puddington L, Wu C, Guernsey L, Gharaee-Kermani M, Phan SH, Thrall RS. Chronic inhaled ovalbumin exposure induces antigen-dependent but not antigen-specific inhalational tolerance in a murine model of allergic airway disease. Am J Pathol 2004;164:295304.

8. Sakai K, Yokoyama A, Kohno N, Hamada H, Hiwada K. Prolonged antigen exposure ameliorates airway inflammation but not remodeling in a mouse model of bronchial asthma. Int Arch Allergy Immunol 2001;126:126-134.

9. Swirski FK, Sajic D, Robbins CS, Gajewska BU, Jordana M, Stampfli MR. Chronic exposure to innocuous antigen in sensitized mice leads to suppressed airway eosinophilia that is reversed by granulocyte macrophage colony-stimulating factor. J Immunol 2002;169:3499-3506.

10. Shinagawa K, Kojima M. Mouse model of airway remodeling: strain differences. Am J Respir Crit Care Med 2003;168:959-967.

11. Johnson JR, Wiley RE, Fattouh R, Swirski FK, Gajewska BU, Coyle AJ, Gutierrez-Ramos JC, Ellis R, Inman MD, Jordana M. Continuous exposure to house dust mite elicits chronic airway inflammation and structural remodeling. Am J Respir Crit Care Med 2004;169:378-385.

12. Kumar RK, Foster PS. Modeling allergic asthma in mice: pitfalls and opportunities. Am J Respir Cell Mol Biol 2002;27:267-272.

13. Wegmann M, Fehrenbach H, Fehrenbach A, Held T, Schramm C, Garn $\mathrm{H}$, Renz H. Involvement of distal airways in a chronic model of experimental asthma. Clin Exp Allergy 2005;35:1263-1271.

14. Moerloose KB, Robays LJ, Maes T, Brusselle GG, Tournoy KG, Joos GF. Cigarette smoke exposure facilitates allergic sensitization in mice. Respir Res 2006;7:49.

15. Vermaelen K, Pauwels R. Accurate and simple discrimination of mouse pulmonary dendritic cell and macrophage populations by flow cytometry: methodology and new insights. Cytometry 2004;61A:170-177.

16. Vermaelen KY, Carro-Muino I, Lambrecht BN, Pauwels RA. Specific migratory dendritic cells rapidly transport antigen from the airways to the thoracic lymph nodes. J Exp Med 2001;193:51-60.

17. D'hulst AI, Vermaelen KY, Brusselle GG, Joos GF, Pauwels RA. Time course of cigarette smoke-induced pulmonary inflammation in mice. Eur Respir J 2005;26:204-213.

18. Curtis JL, Byrd PK, Warnock ML, Kaltreider HB. Requirement of CD4positive T cells for cellular recruitment to the lungs of mice in response to a particulate intratracheal antigen. J Clin Invest 1991;88:1244-1254.

19. Hogaboam CM, Blease K, Mehrad B, Steinhauser ML, Standiford TJ, Kunkel SL, Lukacs NW. Chronic airway hyperreactivity, goblet cell hyperplasia, and peribronchial fibrosis during allergic airway disease induced by Aspergillus fumigatus. Am J Pathol 2000;156:723-732.

20. Tournoy KG, Provoost S, Van Hove C, Joos G. The role of immune tolerance in asthma pathogenesis. Curr Allergy Asthma Rep 2006;6: 437-443.

21. Lewkowich IP, Herman NS, Schleifer KW, Dance MP, Chen BL, Dienger KM, Sproles AA, Shah JS, Kohl J, Belkaid Y, et al. CD4+CD25+ T cells protect against experimentally induced asthma and alter pulmonary dendritic cell phenotype and function. J Exp Med 2005;202:15491561.

22. Hawrylowicz CM. Regulatory T cells and IL-10 in allergic inflammation. J Exp Med 2005;202:1459-1463.

23. Gonzalo JA, Tian J, Delaney T, Corcoran J, Rottman JB, Lora J, Al garawi A, Kroczek R, Gutierrez-Ramos JC, Coyle AJ. ICOS is critical for T helper cell-mediated lung mucosal inflammatory responses. Nat Immunol 2001;2:597-604.

24. Miyamoto K, Kingsley CI, Zhang X, Jabs C, Izikson L, Sobel RA, Weiner HL, Kuchroo VK, Sharpe AH. The ICOS molecule plays a crucial role in the development of mucosal tolerance. J Immunol 2005;175: 7341-7347.

25. Gajewska BU, Tafuri A, Swirski FK, Walker T, Johnson JR, Shea T, Shahinian A, Goncharova S, Mak TW, Stampfli MR, et al. B7RP-1 is not required for the generation of Th2 responses in a model of allergic airway inflammation but is essential for the induction of inhalation tolerance. J Immunol 2005;174:3000-3005.

26. Keir ME, Liang SC, Guleria I, Latchman YE, Qipo A, Albacker LA, Koulmanda M, Freeman GJ, Sayegh MH, Sharpe AH. Tissue expression of PD-L1 mediates peripheral T cell tolerance. J Exp Med 2006; 203:883-895.

27. Freeman GJ, Long AJ, Iwai Y, Bourque K, Chernova T, Nishimura H, Fitz LJ, Malenkovich N, Okazaki T, Byrne MC, et al. Engagement of the PD-1 immunoinhibitory receptor by a novel B7 family member leads to negative regulation of lymphocyte activation. J Exp Med 2000; 192:1027-1034.

28. Koya T, Kodama T, Takeda K, Miyahara N, Yang ES, Taube C, Joetham A, Park JW, Dakhama A, Gelfand EW. Importance of myeloid dendritic cells in persistent airway disease after repeated allergen exposure. Am J Respir Crit Care Med 2006;173:42-55.

29. Hammad H, Lambrecht BN. Recent progress in the biology of airway dendritic cells and implications for understanding the regulation of asthmatic inflammation. J Allergy Clin Immunol 2006;118:331-336.

30. McAdam AJ, Chang TT, Lumelsky AE, Greenfield EA, Boussiotis VA, Duke-Cohan JS, Chernova T, Malenkovich N, Jabs C, Kuchroo VK, et al. Mouse inducible costimulatory molecule (ICOS) expression is enhanced by CD28 costimulation and regulates differentiation of CD4+ T cells. J Immunol 2000;165:5035-5040.

31. Kabbur PM, Carson WF, Guernsey L, Secor ER Jr, Thrall RS, Schramm CM. Interleukin-10 does not mediate inhalational tolerance in a chronic model of ovalbumin-induced allergic airway disease. Cell Immunol 2006;239:67-74.

32. Braun-Fahrlander C, Riedler J, Herz U, Eder W, Waser M, Grize L, Maisch S, Carr D, Gerlach F, Bufe A, et al. Environmental exposure to endotoxin and its relation to asthma in school-age children. $N$ Engl J Med 2002;347:869-877.

33. Gerhold K, Bluemchen K, Franke A, Stock P, Hamelmann E. Exposure to endotoxin and allergen in early life and its effect on allergen sensitization in mice. J Allergy Clin Immunol 2003;112:389-396.

34. Hollingsworth JW, Whitehead GS, Lin KL, Nakano H, Gunn MD, Schwartz DA, Cook DN. TLR4 signaling attenuates ongoing allergic inflammation. J Immunol 2006;176:5856-5862.

35. Schramm CM, Guernsey L, Secor E, Thrall RS. Tolerance induced by chronic inhaled antigen in a murine asthma model is not mediated by endotoxin. Biochim Biophys Acta 2006;1762:499-501. 